\title{
“A CRÍTICA SE SURPREENDE, A CIÊNCIA COMPREENDE": OS IMPASSES DA CRÍTICA LITERÁRIA NO FORMALISMO RUSSO
}

\author{
"Criticism is Surprised, Science understands": \\ Deadlocks of Literary Criticism in Russian Formalism
}

\author{
Priscila Nascimento Marques \\ Rodrigo Alves do Nascimento \\ Universidade Federal do Rio de Janeiro (UFRJ), Faculdade de Letras, Rio de Janeiro, RJ, Brasil \\ E-mail: priscilamarques@letras.ufrj.br \\ Universidade Estadual Paulista (UNESP), Instituto de Artes, São Paulo, SP, Brasil \\ E-mail: professor.rodrigonascimento@gmail.com
}

\section{RESUMO}

O presente artigo tem por objetivo discutir o nascimento da moderna teoria literária, considerando a Escola Formal como ponto de partida da constituição dos estudos literários como disciplina autônoma. Os primeiros movimentos dos teóricos do Formalismo buscaram compor um corpo conceitual próprio e entender o fenômeno literário como algo emancipado de categorias da sociologia, da filosofia ou da psicologia. Tal esforço produziu resultados originais,

EDITORES:

Regina Zilberman

Gerson Roberto Neumann

SUBMETIDO: 13.10 .2020

ACEITO: 03.11.2020

\section{COMO CITAR:}

MARQUES, Priscila

Nascimento; NASCIMENTO, Rodrigo Alves do. "A crítica se surpreende, a ciência compreende": os impasses da crítica literária no formalismo russo. Rev. Bra. Lit. Comp., Porto Alegre, v. 23, n. 42, p. 91-107, jan./ abr., 2021. doi: https:// doi.org/10.1590/2596$304 \times 20212342$ pmrn mas também gerou impasses que estão na base da crise da teoria literária nos anos 1970 e 1980, momento em que emergem as chamadas pós-teorias, que trouxeram para o centro das atenções elementos extra-literários (gênero, política, perspectiva decolonial). Este artigo argumenta que tais impasses se tornaram evidentes já nos primeiros momentos da Escola Formal, quando ela precisou confrontar sua construção teórica com a prática da crítica literária. Ambas as esferas, ao mesmo tempo em que se retroalimentam, explicitavam as deficiências e limites de cada uma.

PALVRAS-CHAVE: crítica literária; teoria literária; formalismo russo; pós-teoria.

\section{ABSTRACT}

The present paper aims at discussing the birth of modern literary theory, taking the Formal School as the starting point of the constitution of literary studies as an autonomous discipline. Russian formalists sought early on to elaborate an original conceptual body to understand the literary phenomena as emancipated from categories borrowed from sociology, philosophy or psychology. Such effort produced ground-breaking results, but also gave rise to deadlocks that are on the base of the crisis in literary theory in the 1970s and 1980s, when post-theories emerged bringing extra-literary elements (such as gender, politics, decolonial perspective) back to the spotlight. This paper argues these deadlocks have become evident in the early stages of the Formal School, when its theoretical construction was confronted with the practice of literary criticism. While theory and criticism fed each other back, the interrelations between them made their own shortcomings and limits explicit.

KEYWORDS: literary criticism; literary theory; russian formalism; post-theory. 


\section{CRÍTICA LITERÁRIA - FUNÇÃO SOCIAL E VALOR}

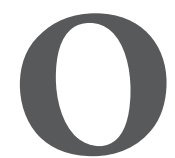

s impasses que cercam o trabalho da crítica literária hoje, muitas vezes restrita ao comentário quase propagandístico de obras ou à hiperespecializada - e não menos mercantilizada - prática acadêmica, empalidecem muito da centralidade que ela ocupou no passado, quando esteve à frente de debates públicos fundamentais e da formação da moderna noção de cultura. Ao que tudo indica, muito desses impasses têm a ver com a crise do próprio objeto literário, que parece ter perdido a centralidade em uma sociedade que atravessa profundas transformações no campo da cultura. A partir daí, tem-se a emergência do campo dos estudos culturais, no qual o universo da imagem tem bastante destaque: "A cultura está se tornando cada vez mais visual e pondo-se cada vez mais em movimento: o cinema, a televisão, a internet e os videogames têm em comum um funcionamento oposto à fixidez da palavra na página, uma superfície branca sobre a qual se imprimem letras normalmente sem um design ostensivo" (DURÃO, 2016, p. 112).

O papel da crítica assumiu feições diversas a depender das diferentes tradições. Não à toa, hoje, o conceito de crítica literária na Alemanha (Literaturkritik) abarca tanto os estudos acadêmicos de obras literárias quanto aquela produzida em jornais. $\mathrm{O}$ mesmo ocorre no Brasil, cuja prática crítica ganhou popularidade em periódicos literários e suplementos culturais de jornais, para depois se tornar típica também da vida universitária. Já no caso do mundo anglo-saxão, ela perdura principalmente no meio acadêmico, a ponto de se tornar sinônimo das próprias noções de teoria e método, e muito raramente se refere à crítica feita em jornais. Por outro lado, no caso russo - que aqui nos interessa de perto -, tal noção é mais ampla e ao longo da história esteve fortemente associada à prática jornalística (DOBRENKO; TIHANOV, 2011, p. ix).

Isso demonstra o quanto a crítica literária não é uma instituição ou prática homogênea e tem relação com as diferentes formas assumidas ao longo do desenvolvimento das instituições. Na Inglaterra, e em grande medida nos principais países da Europa Ocidental, pode-se dizer que ela surge como instituição social a partir da luta contra o Estado Absolutista, nos primórdios do século XVIII. Clubes, jornais, cafés e periódicos conformavam uma "esfera pública” burguesa, um domínio de instituições situadas entre o Estado e a sociedade civil, no qual a crítica se realiza a partir de um discurso comum, pretensamente enunciado de modo equânime entre os indivíduos. Isso significa a formação de uma opinião pública que visava a abolir noções como as de hierarquia e privilégio, típicas de uma sociedade autocrática, em benefício de uma igualdade abstrata - pelo menos no campo do discurso (EAGLETON, 1991, p. 3-9)'.

Desse modo, a crítica - inicialmente tomada em sentido amplo, como crítica cultural e não só literária - torna-se um poderoso instrumento discursivo de unificação de classe, pois sua enunciação pressupunha uma universalidade que era a imagem idealizada da luta burguesa de primeira hora. Nesse momento, o próprio gesto democrático da enunciação tornava-se basilar (e dominá-lo já revelava muito da exclusão de classe ofuscada pelo discurso igualitarista), como se cada indivíduo fosse uma unidade autônoma e livre para produzir seu discurso. $\mathrm{O}$ crítico se tornava então um agente emulsificador e democratizador, cabendo a ele muitas vezes o papel de "educar as camadas médias e tornar a literatura

\footnotetext{
1 Isso porque, como afirma o próprio Eagleton (1991, p. 8), "Não parece que o estado emulsivo da esfera pública se estendesse, para além de pastores e cirurgiões, a agricultores ou criados”.
} 
acessível a um público mais extenso (...)” (DURÃO, 2016, p. 62). Aqui, os periódicos voltados às artes em geral, à literatura e a temas do cotidiano (na Inglaterra, o Tatler e o Spectator foram emblemáticos) tinham um papel fundamental, pois adotavam linguagem acessível e ligeiramente padronizada, enfraqueciam o sistema de mecenato, profissionalizavam a escrita (a figura do gentleman ilustrado é paulatinamente substituída pela do crítico-especialista) e abriam-se à intervenção dos leitores, que de algum modo também exerciam a atividade crítica. Desse modo, o público leitor, não numeroso, mas empenhado, era parte de um circuito de troca de opiniões públicas que progressivamente suplantava o caráter privado ou exclusivo da reflexão. Peter Hohendahl assim resume tal processo:

(...) o moderno conceito de teoria literária está muito atrelado ao surgimento da esfera pública liberal e burguesa do início do século XVIII. A literatura servia ao movimento de emancipação da classe média como um instrumento para a obtenção de autoestima e para articular suas demandas humanas contra o Estado absolutista e a sociedade hierárquica. A discussão literária, que previamente tinha servido como uma forma de legitimação da corte nos salões aristocráticos, tornou-se uma arena para a pavimentação do caminho para a discussão política na classe média. (HOHENDAHL, 1982, p. 52)

Nesse processo, como se vê, o sentido do que se entende por "literário" é alterado. Gêneros e textos que possuíam autoridade inquestionável passam agora pelo crivo da justificativa. A qualidade da obra passa a ser atestada, no gesto de intervenção do crítico, a partir de argumentos expostos racionalmente na esfera pública e não mais a partir da adequação a um modelo. O juízo, ainda que individual, é filtrado pela mediação coletiva. Isso não deixa de ser uma vitória da perspectiva moderna na famosa "Querela dos Antigos e dos Modernos", pois no núcleo do argumento está o "fato", que reivindica os dados concretos de cada época em detrimento da reafirmação de uma base retórica trans-histórica.

Por outro lado, ao longo do século XIX, a consolidação de uma mentalidade cientificista - a mesma que estava na base da racionalidade do crítico - torna-se de algum modo alvo da revolta romântica, que ressalta a subjetividade privilegiada do gênio manifesta na obra. Esta, por sua vez, intensifica-se como objeto autônomo, porque fruto de uma espécie de universo insondável e único. Para Galin Tikhanov (2019), o Romantismo lança as bases de um regime de relevância que toma a literatura por seu valor em si, independente de explicações sociológicas ou históricas. ${ }^{2}$. Desse modo, a crítica desenvolve uma ideia de obra menos "como um espelho que refletisse algo que lhe fosse exterior e mais como uma chama que iluminasse a realidade" (DURÃO, 2016, p. 78). A conduta crítica, portanto, se pauta menos pela demanda da esfera pública comum e mais por uma perscrutação do universo complexo da obra individual. Fruto do gênio, ela precisa de algum modo ser "desvendada", porque em sua tessitura há camadas ocultas de sentido que não podem mais ser captadas pelo simples juízo, mas sim pela interpretação do crítico que de algum modo a confrontará com as questões do tempo histórico. Tal movimento, que estava longe de ser homogêneo ou linear, colocava o crítico em um papel central de intérprete e de atualizador da obra, ou ainda no papel de alguém que poderia legitimar ou rechaçar uma ruptura aparentemente irreversível entre o texto e o mundo. Tal ruptura, inaceitável na Rússia do

\footnotetext{
2 Galin Tihanov se utiliza da expressão a partir conceito foucaultiano de regime de verdade. Em seu esforço de compreensão dos paradoxos fundacionais da teoria literária (como uma manifestação temporalmente limitada, apesar de sua ilusão de atemporalidade), Tihanov sugere que uma determinada constelação de parâmetros sociais e culturais "molda o entendimento e o uso predominantes de literatura pela duração dessa constelação particular", o que significa que a "teoria literária é o produto de uma fase específica na evolução de um regime de relevância particular" que tende a ver a literatura como um tipo de discurso autônomo, diferente dos demais. (TIHANOV, 2019, p. 1-2)
} 
século XIX, então mergulhada no debate sobre o sentido de sua história nacional, colocará o crítico em uma posição estratégia no debate público.

\title{
A TRADIÇÃO DA CRÍTICA LITERÁRIA RUSSA NOS OITOCENTOS
}

Ao longo do século XIX, o ambiente intelectual russo era dominado pelas chamadas questões malditas (prokliátye vopróssy): temas candentes sobre o significado da história nacional, entendida não apenas em uma acepção propriamente historiográfica, mas espiritual, isto é, no sentido romântico de um Espírito Nacional. Os atores deste debate, o meio em que ele se desenvolveu e as características que ele adquiriu em solo russo são bastante específicos. Isso porque os protagonistas de tais discussões foram os membros da chamada intelliguêntsia, uma categoria especificamente russa, que não deve ser confundida com a noção ocidental geral de intelectualidade. ${ }^{3}$ Trata-se de um conjunto de indivíduos que se caracterizam menos por pertencerem a uma determinada classe social ou por terem uma formação acadêmica específica (ainda que implicasse em certo nível educacional), e mais por um tipo de engajamento com os mais urgentes e incontornáveis temas sociais da época. A grande causa do intelliguênt era o povo e as desigualdades que marcavam a sociedade russa:

O intelliguênt era alguém crítico ao regime existente, preocupado com a condição da sociedade, e especialmente com o abismo que separava a elite (incluindo ela mesma) da massa do povo. O intelliguênt era comprometido com a superação desse abismo ao elevar o povo ao nível de uma existência culta e humana. (HOSKING, 2001, p. 264).

E o meio no qual tais embates ideológicos foram travados - a literatura -, ainda que pareça de início semelhante ao meio no qual se travavam os debates no restante da Europa já desde o início do século XVIII, tem aqui tinturas próprias. A despeito da existência de universidades e intelectuais ditos profissionais, parte substancial das disputas sobre temas sociais e políticos ganhou vida pela atividade de literatos. Na realidade paralela da ficção, mediante uso de linguagem esópica (em larga medida devido à atividade constante da censura tsarista), romancistas deram vazão às mais recônditas e tópicas angústias de seu tempo. Tensos conflitos éticos sobre o papel do indivíduo na história, o papel da ciência no desenvolvimento social, a vida do "pequeno homem” (málenki tcheloviék) foram eternizados nos caudalosos romances de Fiódor Dostoiévski, Liev Tolstói e Ivan Turguêniev. Por vezes, as questões malditas receberam formulações bastante diretas - e até literais -, como no caso dos romances O que fazer? (1863), de Nikolai Tchernichévski, e Quem é o culpado? (1846), de Aleksandr Herzen:

\begin{abstract}
A literatura russa, dessa forma, tornou-se o ambiente espiritual no qual foi possível formular as questões mais elevadas da existência humana. Tradicionalmente, essas questões são chamadas “malditas", revelando sua existência predominante nas tradições da cultura filosófica nacional. [...] Isso atesta um tipo de filosofia russa não abstrata, não de gabinete, que, à especulação reflexiva, prefere um pensar filosófico vivo sobre o elevado e o extremo. Esse tipo de filosofia não cabe em tratados [...] Exatamente por isso, como observado por muitos pesquisadores, a literatura se tornou na Rússia a fonte desse experimento moral. (CHEREPOVA, 2016, p. 197).
\end{abstract}

Essa literatura que se estabeleceu como catalizadora de embates éticos, políticos e filosóficos, contudo, é impensável e teria sido inteiramente distinta sem sua contraparte necessária: a crítica literária. As polêmicas no campo beletrístico ganharam forma e seu curso e desenvolvimento foram impulsionados pelas vívidas réplicas

\footnotetext{
3 Segundo Berlin (1988, p. 126) “[o] conceito de intelliguêntsia não deve ser confundido com a noção de intelectuais. Seus membros se consideravam unidos por algo mais que o simples interesse pelas ideias; concebiam-se como uma ordem dedicada, quase como um sacerdócio secular, devotado à divulgação de uma atitude específica em relação à vida, algo como um Evangelho”.
} 
críticas que se sucediam à publicação das obras ficcionais. Ademais, o veículo dessas produções era o mesmo: as chamadas revistas grossas, ${ }^{4}$ vultosas publicações que reuniam textos teóricos sobre política, economia $\mathrm{e}$ ciências, em ensaios, traduções, obras de literatura e, precisamente, ensaios de crítica literária. ${ }^{5}$ Assim, a outra face indispensável da figura do artista - decalcada na Rússia oitocentista a partir da tradição romântica alemã do gênio, visionário, indivíduo com percepção e sensibilidade especiais para as questões humanas e nacionais - era a figura do crítico literário, este também dotado de autoridade moral e algo profética.

Esse tipo de crítica que se dava não em meios estritamente acadêmicos, mas em periódicos de ampla circulação, era conhecido como publicística (publitsístika), um tipo de crítica social que tem como imperativo a vida humana em sociedade. Berlin (1988) a define como gênero crítico que borra as fronteiras entre vida e arte, e hesita em distinguir radicalmente o autor como criador e como cidadão. A obra literária é tida como expressão quase sem mediações da atitude moral do escritor. O publicista-intelliguênt toma parte no processo social. Mais do que mero observador, ele é um "investigador que apreende o mundo e sua época com a força de seu pensamento, aliado ao sentimento, que fala sobre eles aos seus contemporâneos e persegue objetivos civilizadores e didáticos" (POLONSKI, 2008, p. 57).

Certamente, a expressão máxima do publicista-intelliguênt no século XIX na Rússia foi Vissarion Bielínski (1811-1848), figura que se consolidou nos anos de 1840 como mediador social e árbitro literário, cujo veredito era decisivo para o futuro de autores iniciantes. Seu crivo estabelecia a valor estético e social das obras, definia aquelas que se mostravam de fato relevantes e ofereciam uma palavra nova (novoe slóvo). ${ }^{6}$ Contudo, deve-se ressaltar que sua crítica não era meramente conteudista e moralizante. A qualidade artística se incorporava a um juízo totalizante, que não separava o valor poético de uma obra de sua eficácia como instrumento do pensamento social, formando, assim, um todo orgânico entre ética e estética. ${ }^{7}$ Para Bielínski, a literatura tem uma função agregadora; nela, a sociedade, ou uma certa noção de corpo social, é propriamente forjada, pois ela "é uma fonte viva de onde todos os sentimentos humanos e as ideias são difundidos para a sociedade" (BIELINSKI, 2013, p. 122). O poeta é aquele que canta o seu povo e, ao mesmo tempo, atua na feitura de sua autoconsciência.

\section{O FORMALISMO RUSSO: FUNDAÇÃO DE UMA CIÊNCIA DA LITERATURA}

O status assumido pela literatura e pela crítica russas no século XIX tornavam ambas as esferas espaços fundamentais para a formação de um discurso público. Daí o fato de muitos reduzirem todas as preocupações da crítica deste período a problemas de conteúdo ideológico. No entanto, já desde o século XVIII boa parte dos críticos se voltava também a problemas de poética. A crítica anterior a Aleksandr Púchkin (1799-1837) se preocupava largamente com problemas de linguagem e prosódia; e a crítica contemporânea ao poeta estava bastante voltada a questões de gênero e estilo. $\mathrm{O}$ mesmo acontecia, como vimos, com críticos publicistas como

\footnotetext{
4 Sobre o papel das revistas grossas na vida pública russa, o escritor e jornalista Vladímir Koroliénko (1853-1921) afirma: "Muitas condições se reuniram na vida russa para que a se elaborasse o tipo de revista que se desenvolveu entre nós... Na falta de um parlamento ou outra tribuna em que a sociedade pudesse tomar parte na 'palavra ativa' nos destinos da nossa pátria, entre nós, em virtude da própria lógica das coisas, formou-se- um caráter particular da imprensa social e política, expressa de forma mais viva pelas revistas" (KOROLIÉNKO apud KAPUSTINA, 2007, p. 105).

5 Tendo em vista a indistinção entre as diferentes disciplinas na Rússia do século XIX, particularmente entre os profissionais da palavra (jornalista, editor, escritor e crítico), Orlova fala em uma época de "sincretismo filológico" (ORLOVA, 2012a, p. 81).

6 A premência por proferir uma "palavra nova” sentida de forma ubíqua por escritores e críticos russos é expressa, por exemplo, pelo folhetinista de "Dostoiévski (2012, p. 190-191): “Uma palavra nova. Ora, por acaso é possível a gente dizer todo santo dia uma palavra nova, quando talvez passe a vida inteira sem consegui-la e, ao ouvi-la ainda não a reconheça”.

7 Por exemplo, em carta a Nikolai Gógol, Bielínski (2013, p. 149, grifos nossos) exalta o "grande escritor que contribuía tão poderosamente para a autoconsciência da Rússia com sua obra admiravelmente artística e profundamente verdadeira”.
} 
Bielínski, Nikolai Dobroliúbov (1836-1861) e mesmo Dmitri Píssariev (1840-1868), que não eram alheios a questões específicas da forma literária, ainda que ela fosse encarada principalmente nos termos de um veículo para a expressão de uma ideia. (ERLICH, 1981, p. 20-21).

No entanto, é com o movimento simbolista russo que ocorre uma espécie de aliança entre o trabalho artístico e a reflexão formal e filosófica. Além das já conhecidas reflexões de Andrei Biéli no campo da prosa, a maestria parnasiana de Valéri Briússov, a exuberante eufonia verbal de Konstantin Balmont e a força rítmica dos versos de Aleksandr Blók combinavam-se com o empenho dos próprios artistas na reflexão detida sobre o verso e a artesania do poema ${ }^{8}$ - este, um gênero em larga medida sufocado pela preponderância da prosa romanesca ao longo do XIX. Mas não se tratava apenas da preocupação com uma nova forma de expressão, como parecia ser o foco de simbolistas franceses como Verlaine e Mallarmé, mas também da apresentação de uma metafísica, de uma visão de mundo articulada. A disposição trágica e escatológica da filosofia de muitos desses artistas e pensadores se punha em linha com a ideia de Viatchesláv Ivánov de que o simbolismo "não pode ser, e não quer ser, meramente arte” (IVANOV, p. 137 apud ERLICH, 1981, p. 34). Para eles, tratava-se de um nítido esforço de superação das dicotomias positivistas e de articulação orgânica entre som e sentido histórico.

O contraponto direto a essa perspectiva poético-filosófica vem com o Futurismo russo, tendo figuras como Vladímir Maiakóvski à frente, portador de uma verve vanguardista e uma disposição de varrer de cena toda a tradição anterior - seja a do realismo psicológico, seja a da poesia simbolista: "Apenas nós somos a face do nosso Tempo. Nós tocamos a trombeta do tempo na arte literária. O passado é estreito. Púchkin e a academia são mais incompreensíveis do que hieróglifos. Joguemos Púchkin, Dostoiévski, Tolstói e quejandos fora do Vapor da Atualidade." (BURLIUK; KRUCHONYKH; MAIAKÓVSKI, 2017, p. 72). Contudo, o Futurismo não foi capaz de produzir artistas-teóricos da mesma estatura de Ivánov e Biéli, de modo que a tarefa de refletir sobre essa nova forma de expressão coube a jovens estudantes e pesquisadores simpáticos à poesia de vanguarda, que se dispunham a criar todo um novo campo de estudos da literatura - este, por sua vez, também orientado a uma revisão completa da tradição anterior da crítica.

O grupo de estudiosos compartilhava da mesma verve iconoclasta dos formalistas. Sua atitude beligerante inicial tinha a ver com o ímpeto de afirmação de uma nova Escola, o que implicava um nítido esforço de diferenciação, mas era também um sintoma de época. A moderna teoria literária é uma manifestação do entreguerras, que se desenvolveu a partir de uma constelação específica, na qual intelectuais lidam diretamente com a experiência do exílio e da heteroglossia ${ }^{9}$, mas também com a efervescência de movimentos nacionais oriundos do esfacelamento do império austro-húngaro e da própria Revolução Russa. Desse modo, a dialética entre o nacional e o cosmopolita e o sentimento de formação de novas identidades políticas e culturais eram refratários à monoglossia e ao ensimesmamento local da teoria. Ou seja, era preciso falar alto, combativa, sintética e transnacionalmente. Boris Eikhenbaum alguns anos mais tarde, diria em tom de balanço:

Ao discutirmos o método formal e sua evolução, é essencial ter sempre em mente que muitos dos princípios propostos pelos formalistas durante aqueles anos de luta intensa contra seus adversários tinham valor não apenas como princípios científicos, mas também como slogans paradoxalmente afiados com vistas a propaganda e oposição. (EIKHENBAUM, 2002, p. 19)

\footnotetext{
8 Andrei Biéli seria um grande exemplo de articulação entre produção artística e reflexão sobre problemas de poética, como se pode verificar no famoso ensaio "Lirika i eksperiment", de 1909. Disponível em: <http://az.lib.ru/b/belyj_a/text_09_1909_ simvolizm.shtml >. Acesso em 12 de junho de 2020.

9 Galin Tihanov demonstra como a mobilidade de pesquisadores pelo Leste Europeu - muitos deles judeus - existia em um clima de ampla variedade cultural e linguística. Isso não só em relação ao meio que dá origem ao Formalismo Russo e ao Círculo Linguístico de Praga, mas também em relação ao meio que propicia as primeiras formulações no campo do marxismo cultural por Georgy Lukács e no campo da fenomenologia por Roman Ingarden. (TIHANOV, 2019, p. 10-12)
} 
Curiosamente, a fundação de uma autointitulada "Ciência da Literatura" vem casada com um tipo de discurso pouco comum no meio científico: menos a linguagem científica fria e mais o rompante verbal do manifesto. Mas esta não é a única contradição aparente da Escola Formal. Em seu relato sobre a história do chamado Método Formal nos estudos literários até 1927, Boris Eikhenbaum (2002) adverte que este, paradoxalmente, não é um método, mas um esforço de construção de certos princípios teóricos derivados de uma nova orientação no estudo da literatura.

Este paradoxo merece ser destrinchado. Afinal, os jovens estudiosos que passaram a se reunir em torno da Sociedade para o Estudo da Linguagem Poética (conhecida pelo acrônimo russo OPOIAZ) e do Círculo Linguístico de Moscou tinham por objetivo central a instituição do campo dos estudos literários como disciplina autônoma, capaz de se sustentar sobre seus próprios pés conceituais, deixando, assim, de ser mero subproduto de outras disciplinas (como a Estética, a Sociologia, a História e a Psicologia). Neste ensaio posterior aos anos de embate e de sectarismo da Opoiaz, Eikhenbaum, a um só tempo narrador e ator dos eventos descritos, distancia as conquistas do Formalismo de qualquer esquema anterior e anuncia que pretendiam derivar seus princípios do estabelecimento claro de um objeto de estudo, sendo que as ferramentas analíticas decorreriam do contato direto com este objeto.

A ideia de que o Formalismo pretendeu a criação de uma ciência da literatura é confirmada pela associação do surgimento dos estudos formais na Rússia à organização do campo da Kunstwissenschaft, particularmente o estudo das artes plásticas na Alemanha como proposta precursora de uma compreensão da forma artística e sua evolução independente de categorias apriorísticas da Estética. Não por acaso, o termo literaturoviédenie (algo como estudos de literatura, ou Literaturwissenschaft) firmou-se nos anos 1924-1925 (EIKHENBAUM, 2002). Além disso, um claro paralelo entre o Formalismo e as ciências da natureza é estabelecido por Engelgardt em Método formal na história da literatura (1927). Se a alquimia se viu superada pela investigação de cunho científico-objetivo da natureza, o Formalismo realiza movimento análogo ao superar as tendências filosóficometafísicas, psicologizantes e cognitivas no estudo da literatura, que seriam típicas, segundo eles, tanto da tradição publicística quanto da tradição simbolista. $\mathrm{O}$ fenômeno literário e os fenômenos da natureza são colocados lado a lado, no sentido de que ele também pode e deve ser isolado, estudado em seus elementos constituintes, abstraído da totalidade e diversidade de fatores acidentais. ${ }^{10} \mathrm{~A}$ constituição dessa nova orientação para os estudos literários se deu a despeito da coexistência dos "alquimistas da literatura", os quais ofereciam "forte resistência e risadinhas de desdém” (ENGELGARDT, 1927, p. 111) às investidas cientificistas da Escola Formal.

Essa ciência objetiva seria erigida a partir de uma definição o mais clara possível de seu objeto: “[...] o objeto da ciência literária, como ciência literária, deve ser a investigação das propriedades específicas do material literário, de propriedades que distinguem tal material de materiais de tipos diversos" (EIKHENBAUM, 2002, p. 7-8). Não apresenta, portanto, uma definição de literatura, mas o que faz com que determinado texto seja literário, noção cristalizada pelo termo literatúrnost' (caráter literário, "literariedade") cunhado por Roman Jakobson. Na formulação de Engelgardt (1927, p. 105):

A exigência de estudar a obra poética diretamente como tal, específica em sua característica material de constituição pode ser considerada o princípio condutor, o único inabalável e mais eficaz da orientação que se desdobrou naquilo que posteriormente ficou conhecido como Escola Formal: esta é sua palavra de ordem.

A primeira fase de atividades do grupo Opoiaz, entre 1916 e 1921, concentrou-se numa limpeza de terreno e na definição dos pontos de partida diferenciadores. Priorizaram o combate ferrenho à tão próxima e influente

10 São exemplos da inspiração das ciências naturais sobre o Formalismo a busca por regularidades e mesmo a noção de evolução literária (LVOV, 2013, p. 132). 
tradição simbolista, que representava um obstáculo aos estudos do verso. A luta contra eles objetivava "retirar a poética de suas mãos, e libertando-a da relação com teorias subjetivas, estéticas e filosóficas, colocá-la de volta no caminho da investigação científica dos fatos" (EIKHENBAUM, 2002, p. 6). Em termos metodológicos, isso implicava dizer que os simbolistas contaminavam os estudos da palavra poética com o impressionismo de preceitos metafísicos e religiosos (ERLICH, 1981, p. 72). Ao mesmo tempo, afirmavam sua planta-baixa conceitual ao fazerem a distinção entre linguagem prática e linguagem poética (PORMORSKA, 1972). Para a nova Escola, à diferença da linguagem prática, na linguagem poética a função informativa é relegada ao segundo plano e a língua adquire valor autônomo. Assim, a palavra literária se emancipa de toda sorte de vieses filosóficos (religiosos, psicológicos), de biografismos ou mesmo da idiossincrasia do leitor.

Aqui evidencia-se o sentido do paradoxo deste método que não é método: o universo conceitual formalista, inicialmente oriundo da linguística, se propõe científico, mas tem inevitável matriz romântica - a mesma que se fortalece ao longo XVIII e XIX como resistência ao instrumentalismo científico-burguês e conforma um regime de relevância específico (TIHANOV,2019). Isso porque, ao diferenciar a linguagem poética da linguagem prática a partir de sua função, ou seja, nos termos de uma autotelia e não de uma heterotelia, os formalistas revivem a própria definição de belo na arte formulada por românticos alemães como Karl Philipp Moritz, para quem a "ausência de finalidade externa deve ser compensada, na arte, por uma intensificação da finalidade interna"; ou como August Wilhelm Schlegel, que "justifica precisamente as repetições fônicas (as exigências métricas do verso) pela necessidade de afirmar o caráter autônomo do discurso poético" (TODOROV, 2015, p. 30-31).

No entanto, tal filiação inesperada não significa identidade, de modo que noções como intuição ou genialidade, típicas da concepção romântica, são descartadas como fontes para o correto entendimento da literatura. A materialidade da obra passa a ocupar o centro da investigação; ou seja, o Formalismo se propunha a um novo entendimento da forma artística. Esta deixa de ser mero invólucro ou veículo de determinado conteúdo (significado, imagem, ideia), como de algum modo preponderou entre a crítica russa do XIX, e passa a ser vista como totalidade concreta e dinâmica, ela mesma portadora de sentido. Como especificidade da arte, a forma revela um uso especial do material, de modo que "era preciso concretizar o princípio da perceptibiliade da forma para que fosse possível adentar a análise da própria forma, entendida como conteúdo" (EIKHENBAUM, 2002, p. 13).

O impulso de união orgânica era semelhante ao dos simbolistas, mas em chave bastante diversa. Isso porque, superada a oposição entre forma e conteúdo, surge a díade material vs. procedimento (prióm). O primeiro, originado da cultura, da língua, da tradição, não é, em si mesmo, de interesse primordial para o formalista; já o procedimento, isto é, a organização específica do material na obra literária, constitui o âmbito a ser destrinchado analiticamente. ${ }^{11} \mathrm{E}$ tal análise, baseada no rigor científico, é o que torna muitas vezes o Formalismo mais positivo que o próprio Positivismo: no afã de ser até mais rigoroso que este último, tira de cena as questões de "raça", "meio" e "momento" supondo um esquema ultra-abstrato de recorte do objeto.

Contudo, isso não implica dizer que o Formalismo foi apenas uma fenomenologia da literatura. Não se restringiu à descrição dos procedimentos em estudos sobre o som no verso ou à construção do enredo na prosa. Segundo Pormoska (1972, p. 55-57), com Iuri Tyniánov, já a partir de meados dos anos 20, eles foram estudados também em termos de suas relações funcionais, que poderiam ser construtivas (como os elementos se articulam dentro de uma obra), literárias (como eles dialogam com o sistema literário); e discursivas (relação entre a obra e o material linguístico). Desse modo, o método formal (em oposição ao método genético)

11 Não à toa, o texto "Arte como procedimento", escrito em 1917 por Viktor Chklóvski (2019), é considerado uma espécie de manifesto do Formalismo, ainda que, como já bastante notado, algumas de suas categorias, como a de "estranhamento", não tenham sido definidoras do edifício teórico dos demais formalistas. 
buscou criar uma teoria literária capaz de revelar o objeto de estudo e uma história da literatura, que verifica o desenvolvimento desse objeto na história.

No entanto, as contradições do Formalismo não estavam só na relação conflituosa entre tom inflamado e linguagem objetiva, muito menos restritas às dificuldades de conciliação de um aparato científico com sua episteme romântica. Isso porque, no momento em que uma teoria que se pretende objetiva precisa lidar com as demandas da crítica literária, ou seja, operar com a noção incontornável de valor, projeta-se uma vinculação do objeto com aquilo que lhe é exterior, de modo que um novo leque de impasses se impõe no edifício conceitual formalista

\section{FORMALISMO E CRÍTICA LITERÁRIA: O CASO DE BORIS EIKHENBAUM}

O caminho do Formalismo rumo à instauração de uma ciência (ou teoria) sobre a literatura, constituída como campo autônomo e munido de aparato conceitual próprio, levou, como vimos, a uma inevitável "abstração forçada” (ENGELGARDT, 1927) e a uma ruptura com outras tradições e formas de pensar o objeto literário. Esse grito de independência em relação às outras esferas revelou-se especialmente problemático no caso da crítica literária.

A emergência do Método Formal no cenário dos estudos literários com sua ênfase numa análise de cunho objetivo e material não alterou essencialmente o escopo e a função essencial da crítica literária, isto é, seu caráter essencialmente valorativo e subjetivo, bem como sua função social de transpor para a contemporaneidade, ou de atualizar, o sentido de uma determinada obra. Ao contrário, "no campo do cotidiano literário (literatúrnyi byt), os formalistas estudaram a crítica como 'instituição', como um dos principais transformadores e filtros que ligam o artefato à percepção" (HANSEN-LÖVE, 1985, p. 96). Assim, por suas características e função, a crítica "não pode ser (e nunca foi) científica, ligando-se, antes à esfera da vivência estética (artística) pela consciência social” (ENGELGARDT, 1927, p. 115).

Isto não quer dizer que o Formalismo não tenha marcado um antes e um depois no trabalho da crítica, visto que opera uma inversão na valência de cada polo: se antes os procedimentos da crítica ocupavam o território da ciência, com o advento da Escola Formal, a ciência "se apossou da liberdade da crítica" (Engelgardt,1927, p. 114), impondo limites ao impressionismo e subjetivismo, e convocando uma atenção especial à poética no trabalho de julgamento. Assim, seria possível manter na crítica os mesmos preceitos e abordagem da literatura após o estabelecimento de conceitos como procedimento literário, função poética e literariedade?

A mútua interferência entre essas esferas foi atestada por Eikhenbaum (2002), que fala de uma aproximação entre ciência e crítica, ou, nas palavras de Hansen-Löve (1985, p. 96), do fato de que a crítica se torna "ciência aplicada”. Ademais, a interpenetração entre essas esferas é confirmada por um fato decisivo: os teóricos do formalismo eram, eles mesmos, críticos bastante ativos. Óssip Brik, por exemplo, atuou de modo direto no front cultural da Revolução de Outubro e depois como principal porta-voz da revista LEF ${ }^{\mathbf{2}}$, para a qual escreveu assiduamente. Não só o fizeram, como pontualmente ensaiaram reflexões sobre o fazer crítico. Emblemáticos deste esforço são dois textos de Boris Eikhenbaum: "Discurso sobre a crítica", de 1918, e "A crítica é necessária", de $1924^{13}$.

No primeiro deles, publicado inicialmente na revista Dielo Naroda (Assunto do Povo) a reflexão sobre as tarefas da crítica vem atravessada pelo rompante iconoclasta que marcou os anos iniciais da Opoiaz e está em forte simbiose com o tom rebelde e de manifesto é dos Futuristas - não à toa, a ligação é evocada textualmente

\footnotetext{
12 Revista da Liévyi Front Iskusstv (Frente de Esquerda das Artes), publicação surgida em 1923 que se tornou um verdadeiro fórum de debate sobre a arte de vanguarda e seu papel social.

13 A tradução integral de "Discurso sobre a crítica" e "A crítica é necessária" está incluída no presente número desta revista.
} 
por Eikhenbaum. ${ }^{14}$ Se os Futuristas se rebelaram contra a tradição em busca de novas formas de criação literária, os críticos voltavam sua fúria contra a longa tradição da intelliguêntsia, consolidada ainda no século XIX, o que significava, na prática, "uma recusa a todo sistema de valores morais, visão de mundo e de obrigações do intelliguênt russo” (LVOV, 2013, p. 151).

No ensaio, Eikhenbaum propõe não só botar abaixo a tradição anterior, mas saudar os representantes do novo: "Todas as esperanças estão num turbilhão fresco de barbárie, que nos traga das distantes estepes sementes novas" (EIKHENBAUM, 1987, p. 328). Tal qual o artista de vanguarda, o teórico formalista considera que tudo o que foi pensado sobre a arte até então não passa de "mentiras". Nesse sentido, é preciso abandonar não só a ideia de uma arte que convive pacificamente com a ordem das coisas (e o Simbolismo, é possível inferir, seria exemplo dessa arte voltada para o grande ofício do Belo e para um Absoluto maior), mas também a ideia de uma crítica que organize ou torne a arte inteligível. Se para os Futuristas só a barbárie pode salvar a arte, para o crítico a selvageria deve povoar o próprio processo de elaboração crítica.

Incorporada ao trabalho, a barbárie demonstraria a disposição de sintonia do crítico com as demandas do tempo. A Revolução então fresquíssima - de algum modo em curso se tomarmos a Guerra Civil como processo de consolidação do ideário bolchevique que duraria até 1922 - era uma "pancada na cabeça” (Eikhenbaum, 1987, p. 329), uma bofetada dada pela história, mas que passa a ser considerada "uma tragédia necessária”. Ou seja, para Eikhenbaum um fato é inegável: há agora uma incontornável nova forma de vida. ${ }^{15} \mathrm{O}$ crítico deve, portanto, abraçar suas novas tarefas - as mesmas que, evidentemente, já estavam sendo encampadas pela Escola nascente: "entre nós haverá em breve uma nova crítica e uma nova história da literatura". (EIKHENBAUM, 1987, p. 328)

E se a Escola Formal se encontrava em um momento fundamental de definição do campo, dedicandose à descrição do objeto literário a partir de um universo conceitual objetivo, científico, ao crítico caberia um novo ponto de partida: não mais ler a obra literária para, por trás da forma, procurar um conteúdo (o que, segundo ele, sempre levou o intelliguênt russo ao gesto reprovável de distorção da própria obra em prol de uma ideia prévia), mas sim reconhecer que não é possível entendê-la de todo. Propõe que o crítico recuse a tarefa de interpretar e julgar, que "se recuse a tentar elucidar o sentido da obra por meio da 'tradução' desse sentido em seu 'idioma’ próprio” (LVOV, 2013, p. 154). Para Eikhenbaum, Tolstói já teria apresentado tal programa ao reivindicar uma crítica de arte que não buscasse "guiar o leitor" no "labirinto de entrelaçamentos" de que é feita a obra. Ao crítico caberia demonstrar o próprio absurdo de se buscar ali qualquer pensamento; isso porque

(...) cada pensamento, expresso em palavras de maneira isolada, perde seu sentido, decai terrivelmente, quando é retirado dessa corrente em que se encontra. A própria corrente é composta não apenas de pensamento (...), mas de alguma outra coisa, e é impossível explicar o princípio desse entrelaçamento diretamente com palavras. (TOLSTÓI apud EIKHENBAUM, 1987, p. 329)

Como representante de uma ciência nascente, a comparação com outras ciências objetivas parece fundamental. Tal qual o cientista que não entende de todo a natureza, mas conhece suas leis, o crítico deve não só dominar tais leis (aquelas, evidentemente, descritas pelo próprio Formalismo), mas revelar ao leitor que uma obra visa a enganar e dificultar qualquer entendimento. $\mathrm{O}$ escritor quer dar ao velho um sentido novo, quer propor novos vínculos e inventar expressões; por outro lado, o leitor terá sempre a falsa sensação de que "entende" o que ocorre, já que é sempre movido por uma intenção prévia à leitura, por uma busca de elementos que falem algo para si, que o eduquem ou que apontem caminhos diante dos impasses da História.

14 "Os futuristas têm bons aforismos. Um deles merece ser citado: 'Com frequência, apenas a barbárie pode salvar a arte'. Vivemos nessa época.” (EIKHENBAUM, 1987).

15 "Nós pensamos de outra forma, falamos de outra forma, e vivemos de outra forma". (EIKHENBAUM, 1987, p. 329) 
Ao crítico - esta figura comprometida menos com o artista e mais com a "criação genuína" e com o leitor (EIKHENBAUM, 1987) - caberia, portanto, demonstrar o quanto isso é apenas uma visão muito restrita e distorcida da literatura.

No entanto, ainda que este ensaio de 1918 apresente uma urgência em relação à instauração de um novo programa crítico e que a própria realidade pareça não permitir seu adiamento, a sensação de que a crítica adequada ainda não existe continuaria seis anos mais tarde, em 1924, quando Eikhenbaum publicou o ensaio "A crítica necessária”, no periódico Jizn Iskusstva (Vida da Arte). A percepção da falta é reveladora do quanto a dimensão da crítica ainda era uma espécie de nó para a Escola Formal, então vivendo uma de suas fases mais produtivas. Afinal, todos os anos anteriores estiveram voltados para a definição de uma ciência que "saiu da lamentável posição de lacaia de outras ciências” (EIKHENBAUM, 1924, p. 12); contudo, ao voltarem todos os seus esforços para a definição de seu objeto, a reflexão sobre uma dimensão que lida justamente com forças extraliterárias - aquelas que, segundo eles, foram responsáveis pela percepção subjetiva do fenômeno literário - parece ter ficado obliterada ou intencionalmente negligenciada.

Neste segundo ensaio, diferenças de tom e da própria função da crítica ficam evidentes em relação ao ensaio de 1918. O primeiro movimento observado entre um e outro é a passagem de uma posição negativa/ reativa para uma atitude propositiva por parte do crítico. Se no primeiro ensaio temos um exemplo típico daquilo que Medviédev (2012) chama de método apofático, isto é, de definição pela negação, que metodologicamente se revelou entre os formalistas na definição de linguagem poética pela oposição (ou negação) à noção de linguagem prática, no segundo ensaio, justamente por estarem mais claras as necessidades de época e as leis que regem a série literária, o crítico passa a ser uma figura que visa não à demolição, mas à sugestão de caminhos.

Afinal, agora não é necessária uma diferenciação em relação às tradições anteriores, que parecem estar sendo superadas pelos processos históricos. O dado aparente é que o público leitor deixou de acreditar na literatura russa e que "não voltará a ela enquanto não surgir uma nova crítica” (EIKHENBAUM, 1924, p. 12). Por isso, neste período posterior à Guerra Civil, em que de algum modo o establishment soviético se volta às demandas de consolidação da sociedade socialista, o que incluía no debate oficial a necessidade de uma "cultura proletária”, escritores parecem buscar a forma necessária para uma "época da necessidade" - e para Eikhenbaum, a crítica encontra-se mergulhada neste mesmo pathos de busca.

Qual seria então a forma necessária para o crítico? Para o teórico formalista, ela não pode partir de um sistema de avaliação baseado no "gosto", no estabelecimento de um ranqueamento ou na simples indicação impressionista do que é bom ou ruim. Sua avaliação é fruto de um talento especial, de um "senso de contemporaneidade" objetivo que apenas o bom crítico possui. Ou seja, diferentemente do historiador da literatura, que tem seus olhos postos no passado e para aquilo que já foi formado, o crítico se converte naquela figura que, munida da capacidade de perceber as linhas de força de sua época, reage para "discernir os elementos da forma necessária" (EIKHENBAUM, 1924, p. 12).

Desse modo, ao sair do campo do gosto para se sintonizar com a ciência - que também não deixa de fazer suas avaliações e seleções metodológicas diante de uma realidade inesgotável em termos de material -, o crítico entende, determina e avalia o que está em formação diante dos seus olhos, mas que ainda não se constituiu de todo. Avalia o que está em processo para perceber as demandas da história e somar esforços com os criadores. Tem-se aqui, portanto, uma mudança fundamental no tipo de interlocução estabelecida. Se antes a função da crítica estava em desestabilizar o edifício interpretativo do leitor, agora ela está em uma espécie de guia e de "assessoramento" objetivo do escritor. Isso porque, para o teórico russo, a paixão do escritor está menos na obra em si e mais na descoberta da "forma necessária”, a mesma que é "aguardada pela história" (EIKHENBAUM, 1924, p. 12). 
Neste caso, fica evidente que Eikhenbaum anseia que a crítica se aproxime da ciência ${ }^{16}$ menos por enxergar a teoria formal como um determinante da crítica e mais por ver que é possível constituir uma "rede de entrelaçamentos" entre ambas, para ficar na metáfora tolstoiana. Isso porque o espírito inicial do Formalismo de desbravamento da forma artística une de maneira bastante imbricada uma postura que é a um só tempo científico-objetiva e crítica, ainda que não voluntária, que implicou a adoção de duas atitudes complementares: uma postura estranhadora do texto e uma postura construtiva, isto é, propositiva (LVOV, 2013). Como vimos, o primeiro texto de Eikhenbaum encontra-se embebido dessa primeira postura, qual seja, de um pathos estranhador: propõe ao crítico um olhar "ingênuo", livre de preconceitos filosóficos e sociológicos, voltado à materialidade do objeto artístico.

Se no plano teórico os formalistas desvendaram o conceito de estranhamento (ostraniénie) como um dos procedimentos pelos quais artista apresenta o real, no plano crítico essa descoberta conceitual ecoa como uma convocação a um olhar novo, estranhador, para a realidade literária. O bárbaro e o selvagem de que fala Eikhenbaum em "Discurso sobre a crítica" é o único capaz de lançar um "olhar fresco para a arte como sistema de procedimentos" (ORLOVA, 2012b). Assim, nesse momento, tanto o teórico como o crítico se voltam, cada um ao seu modo, para o campo da recepção. O teórico presume um leitor abstraído, idealizado; o crítico fala a um leitor concreto, ligado diretamente ao seu tempo. Contudo, ambos se voltam simultaneamente para a obra literária em sua construção formal. Trata-se, portanto, de uma visão com olhos postos na recepção e nos mecanismos imanentes da arte: “o crítico, assim como o artista, fala sobre a arte 'de dentro', partindo de sua especificidade interna” (LVOV, 2013, p. 155).

Não obstante, a aparência externa e o resultado objetivo desse mesmo impulso desbravador que toma crítica e teoria são bastante distintos. $\mathrm{Na}$ teoria, surgem análises descritivas meticulosas sobre o problema do som no verso e sobre a poesia transmental (zaum); estudos que se restringiam mais ao aspecto exterior e advogavam o predomínio da palavra sobre o sentido e uma autotelia estética. Assim, o teórico descobre como a arte é feita e que efeitos na percepção do receptor ela é potencialmente capaz de suscitar. Instigado por essa descoberta, o crítico convoca o leitor a fazer movimento análogo: simplesmente olhar a obra, sem buscar nela sentidos exteriores.

Fundado nessa complementariedade e interdependência entre teoria e crítica, Eikhenbaum chega a uma formulação lapidar: "a crítica se surpreende, a ciência compreende" (EIKHENBAUM, 1922, p. 9). É o que Lachmann (1970) propõe como uma associação entre surpresa e estranhamento diante da amarração de elementos díspares numa obra. Tal associação entre crítica e surpresa é também feita pelo próprio Chklóvski (1966, p. 201), para quem "A surpresa é a descoberta da distância entre si e o fenômeno; é a crítica do fenômeno, sua avaliação. A surpresa é um dos objetivos atingidos pela construção dos acontecimentos, sua sequência e relação contraditória”.

Assim, de maneira conclusiva, no final do "Discurso sobre a crítica”, Eikhenbaum atribui funções claras para escritores e críticos, expondo ao mesmo tempo uma escala de valor para o que considera relevante na produção artística: o escritor é responsável pela criação de procedimentos sempre renovados de elaboração do material verbal, pela subversão da tradição e construção de novos becos e encruzilhadas no grande labirinto que é a arte; crítico, por sua vez, não constrói o labirinto, não desmascara a arte, mas mostra que "o leitor está nu”, apontando que o caminho literário não é linear e evidente, não leva a sentidos exteriores ou não dá lições civilizatórias.

Por outro lado, se no "Discurso sobre a crítica” Eikhenbaum ataca a capacidade hermenêutica do crítico e do leitor, ou ainda, sua capacidade de enxergar algum sentido que lhe seja exterior, em "A crítica é necessária”,

\footnotetext{
16 Por exemplo em: "Unir o trabalho em periódicos e o científico é meu ideal” (EIKHENBAUM apud ORLOVA, 2012b). Ver também “Teoria do método formal".
} 
o autor se volta contra outro pilar da atividade crítica: a necessidade - incontornável a priori - de emitir juízos de valor sobre a obra. O crítico não é professor, tampouco o leitor é seu aluno. A figura análoga ao crítico é, antes, a do historiador, com o diferencial que o crítico reconhece e analisa os fatos não do passado, mas as linhas de força do presente.

A evocação da figura do historiador não é gratuita. Ela se encontra afinada com os desenvolvimentos teóricos do Formalismo nos anos vinte, particularmente com o impulso de olhar para a forma artística a partir de seu dinamismo evolutivo. Trata-se do momento em que o Formalismo amplia seu campo de interesses da teoria para o da história da literatura, esta tomada não como disciplina ou tema em si, mas como uma nova dimensão para o estudo da literatura (EIKHENBAUM, 2002). Ademais, trata-se de uma visão de história que não se caracteriza por uma sucessão de fatos, mas por uma luta entre forças de sentidos distintos. ${ }^{17}$

O teórico olha presente e passado buscando compreender a evolução da forma e as modificações na função literária de tal ou qual procedimento; o crítico move-se do presente para o passado e tem o futuro como horizonte. Para o crítico, a contemporaneidade é, pois, uma esfera prenhe de tensões, o campo de batalha atual no qual ele opera. Vê-se, aqui, um aceno à ideia de função social da crítica, no sentido de sua dimensão propositiva. A ação prática do crítico se reveste novamente de uma função social, desta vez munida de um entendimento acerca do fenômeno literário oriundo das formulações teóricas da Escola Formal.

Nesse caso, o que permite ao crítico converter-se em agente do processo histórico é sua presença orgânica na contemporaneidade decorrente da própria natureza de seu ofício. Ele deve ser consciente de si mesmo como representante de uma determinada época. Contudo, é a partir daí que os contornos que separam crítica e teoria tornam-se difusos, pois, como já vimos, a teoria formalista em sua origem é marcada igualmente por um senso aguçado das tendências da contemporaneidade, visto sua ligação direta entre o desenvolvimento da Escola Formal e os experimentos futuristas na arte - a ponto de, muitas vezes, poetas futuristas declamarem versos e teóricos formalistas explicarem "como se fazem versos" em um mesmo sarau.

Para Eikhenbaum (1924), a principal função do crítico é captar o processo presente de formação dos indícios daquilo que no futuro será objeto da história da literatura. Ele é, assim, uma espécie de "historiador do futuro". A plena execução dessa tarefa está associada, para o autor, a uma estreita associação com a ciência:

Como podem ver, isso já não está tão longe da ciência. Não existe história livre de paixões e julgamentos. O historiador é, inclusive, obrigado a avaliar os fatos, do contrário ele nem sequer terá fatos, pois a realidade mesma, por si só, é inesgotável. Tudo se resume, justamente, a que, na atual situação, a crítica deve se aproximar da ciência. A ciência literária saiu da lamentável posição de lacaia de outras ciências e se aproximou dos problemas que dizem respeito tanto ao passado quanto ao futuro. Com isso, é superada a distância que antes separava o cientista acadêmico do crítico tagarela. O período da crítica "do leitor" acabou: são necessários profissionais autorizados, aos quais poderiam recorrer também os escritores, cuja ardente paixão é menos o invento do que a descoberta da forma devida, pois ela é omitida pela história. (EIKHENBAUM, 1924, p. 12).

Assim, a crítica não é vista como disciplina autônoma, mas como um gênero, ou seja, uma das possíveis manifestações da própria literaturoviédenie, na medida em que deve ser uma crítica da forma. ${ }^{18} \mathrm{Um}$ dos argumentos em defesa dessa posição considera que não há críticos que sejam apenas críticos, pois a despeito da forte

\footnotetext{
17 Numa análise comparativa de dois textos de Eikhenbaum sobre Lérmontov, datados de 1924 e 1941, Pinto e Francisco Júnior observam como a análise de cunho histórico se torna cada vez mais importante na produção deste autor, na qual se verifica "um profundo e enraizado historicismo [...] segundo o qual a obra deveria ser entendida estritamente no seu contexto original, diante do cânone que a havia gestado e da tradição específica que a obra se propunha a negar" (PINTO; FRANCISCO JÚNIOR, 2018, p. 44).

18 Trata-se de uma ideia discutida no texto "Pogovorim o nachem remesle" (Falemos sobre o nosso ofício), publicado em 1945 por Eikhenabum (cf. ORLOVA, 2012b)
} 
oposição ao modelo do século XIX por sua inespecificidade literária, o Formalismo não leva à constituição de uma crítica como matéria independente. Com a Escola Formal, a crítica é convocada a se tornar uma de suas esferas de atuação, uma ciência aplicada.

Outra especificidade importante da atividade crítica apontada pelo Formalismo é o veículo pelo qual ela se manifesta: os periódicos ou revistas literárias. A face social do trabalho do crítico se afirma pelo caráter ampliado de seu público-alvo, que não é estritamente acadêmico. É reforçando o papel das revistas que Eikhenbaum encerra "A crítica é necessária". Ele nomeia essa esfera de atuação do estudioso da literatura como jurnálnaia naúka (ciência de periódico), isto é, uma ciência que se coloca a serviço do debate público, que se projeta para fora do estudo imanente do objeto e busca dialogar - servir - ao escritor. Munido, por um lado, de um entendimento científico e objetivo do processo literário, e, por outro, de uma sensibilidade ao campo de forças em jogo processo literário presente, o crítico lança seu olhar sobre a obra. Assim, o desdobramento da teoria literária em uma ciência de periódico, "impediu os membros da Opoiaz de se isolarem em seus próprios métodos, fugindo da contemporaneidade, e conferiu às suas buscas uma paixão axiológica oriunda da crítica” (LVOV, 2013, p. 134).

Dessa forma, o crítico se revela figura-chave na superação da crise na literatura, à qual Eikhenbaum se refere no início de seu ensaio de 1924. É a instância à qual o escritor pode e deve recorrer para esclarecer possíveis caminhos renovados a serem trilhados:

O escritor, hoje, não apenas escrevinha, mas busca a forma necessária. Esse pathos de busca tensa o aproxima do crítico. A crítica é necessária hoje não apenas ao leitor, mas ao escritor. A história lançou um enigma que deve ser resolvido por meio de esforços conjuntos. (EIKHENBAUM, 1924, p. 12).

É nessa confluência de um pensar científico e uma espécie de ativismo literário que se encontra um dos paradoxos do Formalismo, algo que Medviédev (2012, p. 243) definiu como uma "posição ambígua e absurda entre a ciência e a corrente literária militante”. Além disso, segundo Medviédev (2012, p. 243), com os formalistas, "a crítica perde suas funções e o seu principal papel de ser mediadora entre, por um lado, as exigências sociais e ideológicas gerais da época e, por outro, a literatura”. Se a acusação de militância se revela consistente, em particular se levarmos em conta as origens do Formalismo e a estreita ligação com o Futurismo, por outro, a suposta alienação em relação às exigências sociais e ideológicas talvez não seja igualmente justa (inclusive em virtude da justiça da primeira acusação).

Um fato que incomoda aos críticos do Formalismo é que, em particular no plano teórico, as premissas históricas e sociológicas estão apenas implícitas e, se formos justos, não plenamente desenvolvidas. ${ }^{19}$ No "Discurso sobre a crítica" o acontecimento fundamental - não nomeado - que engendra o argumento da necessidade de uma nova crítica e que configura ponto de virada na história russa é, sem dúvida, o processo revolucionário de 1917, a partir do qual se instaura uma realidade de crise, de colapso (não apenas transformação), que exige reformular de maneira radical e profunda a sociedade, e, consequentemente, o modo de apreender a arte. Em "A crítica é necessária”, o autor pressupõe que o crítico tenha um sentido agudo das forças históricas em operação no presente. Novamente, uma apreciação oblíqua, mas fundamental sobre o contexto social: "Vivemos a época do dinamismo, a época da necessidade. Nada permanece firme no lugar. Mesmo nosso dinheiro não pode apenas 'ficar' no bolso, ele ao mesmo tempo cai e sai voando para o alto. Este é o símbolo dos nossos dias" (EIKHENBAUM, 1924, p. 12). Assim, nesse mundo em que tudo que é sólido desmancha no ar, a atitude beligerante do formalismo deve ser ela mesma vista como ato político, como defende, por exemplo, Olga Kempinska (2018).

19 Uma síntese de algumas das críticas dirigidas aos formalistas oriundas de diferentes fronts pode ser vista em Kempinska (2018). 


\section{CONSIDERAÇÕES FINAIS}

Se, por um lado, o Formalismo constitui uma das principais linhas de força da moderna teoria da literatura, por outro, os teóricos desta nova ciência não deixam de derivar seus conceitos de um regime de relevância muito mais longevo. Recuperam o impulso romântico de autonomização da obra, mas repelem as análises sociais ou metafísicas da literatura que vigoraram no século XIX. Propõem um tipo de abordagem científica e objetiva, com descrição pormenorizada dos componentes da obra, insistindo sempre no caráter autotélico desta linguagem, de modo que o diálogo com qualquer outra disciplina ofuscaria uma correta apreensão do fenômeno literário. Ao fazê-lo, galgaram um nível de abstração conceitual inédito nos estudos literários, tornando-se um dos flancos mais vigorosos do movimento de racionalização da teoria e das artes no século XX. Por isso mesmo, tal empreitada está repleta de impasses. Um dos principais, como vimos, se dá na sua obtusa relação com a questão do valor - aspecto essencial do trabalho crítico.

A despeito de proporem a fundação de uma ciência objetiva, os formalistas revelam em suas definições uma afinidade, por vezes até militante, com as expressões poéticas de vanguarda. Ou seja, a ambição de cientificidade se chocou com a inevitabilidade da valoração estética. De qualquer modo, o que pudemos verificar na comparação entre os poucos - mas iluminadores - textos reflexivos do Formalismo sobre a função da crítica, aqui representados por dois ensaios de Boris Eikhenbaum, é que essa tensão gerou insights inovadores. No primeiro ensaio do teórico, em sintonia direta com as primeiras formulações da Escola Formal, a função do crítico seria a de produzir um estranhamento no leitor, então acostumado a leituras dirigidas da obra, revelando-lhe a rede de entrelaçamentos que a constitui e que desestabiliza qualquer asserção definitiva. Há aí, evidentemente, uma simbiose entre uma perspectiva teórica e uma posição de valor: a experimentação formal que caracterizava o Futurismo russo era também parte da definição formalista sobre a essência do fazer artístico; do mesmo modo, o estranhamento gerado no processo de leitura por meio e um procedimento literário inusitado era o mesmo mobilizado pelo crítico para desestabilizar os entendimentos consolidados do leitor.

Mais tarde, seguindo a trilha dos desenvolvimentos da própria teoria, Eikhenbaum demonstraria que o conhecimento técnico sobre a literatura em sua especificidade deveria estar aliado a um senso do contemporâneo e da própria série histórica, convertendo a atividade crítica em ferramenta prático-política de ação sobre a realidade: o crítico, que era a ponte entre obra e leitor, expande seu campo de influência e se lança como elo entre a obra e o próprio ato criativo futuro. Ele se converte em farol para o escritor. Ironicamente, é esta postura de "farol" empenhado no presente que levará muitos críticos contemporâneos do Formalismo, como Medviédev, a acusá-los de militantes velados da poética futurista. Por outro lado, o burocratismo soviético - que acabará oficialmente com o grupo no início dos anos 30 e forçará sua retratação pública - passaria a acusá-los de adoradores da forma, de figuras escapistas ou isentas das grandes disputas da História.

De qualquer modo, o que se pode perceber é que a crítica literária - justamente a dimensão menos explorada pela pesquisa formalista - foi a responsável não só por explicitar os impasses de uma teoria que se pretendia científica, mas também introduzir a história a contrapelo na própria teoria. Este movimento aparentemente involuntário, mas bastante produtivo, advém do envolvimento agudo dos formalistas com as tendências fortes de seu tempo - disposição visível sobretudo em "A crítica é necessária", de Eikhenbaum. Assim, se aceitarmos a tese de Tihanov (2019) sobre a emergência do Formalismo num ponto de transição entre dois regimes de relevância (da compreensão da literatura por seu valor extra-estético ao estudo de seu valor autônomo) e, ademais, como um processo não desprovido de inconsistências e de uma paulatina moderação de propósito, pode-se concluir que o fator fundamental gerador de tais impasses e oscilações foi a atividade crítica. Tendo como munição um conhecimento teórico preciso sobre a arte literária, o crítico precisa ir além. Novamente, ele se vê às voltas com a necessidade de pronunciar uma palavra nova. 
Desse modo, se para os próprios formalistas isso talvez constituísse uma verdade embaraçosa, para nós, tomada a devida distância, isso revela o quanto a teoria, por mais que se proponha ser objetiva, não está livre dos julgamentos de valor - não à toa, a própria crise da teoria a partir dos anos 1970 se daria em função de sua dificuldade de abarcar as demandas nascidas do processo de descolonização e das frentes que exigiam a politização de métodos e critérios de análise. Da mesma forma, tal processo explicitou o quanto a crítica, se distante da dinâmica imanente do objeto, pode se reduzir facilmente aos caprichos arbitrários e impressionistas do crítico.

\section{REFERÊNCIAS}

BERLIN, I. O nascimento da intelligentsia russa. In: Os pensadores russos. São Paulo: Companhia das Letras, 1988, p. 115-146.

BIELÍNSKI, V. Carta a Nikolai Vassílievitch Gógol. In: GOMIDE, Bruno (org.). Antologia do pensamento russo. São Paulo: Editora 34, 2013, p. 147-159.

BIELÍNSKI, V. Pensamentos e observações sobre a literatura russa. In: GOMIDE, Bruno (org.). Antologia do pensamento russo. São Paulo: Editora 34, 2013, p. 113-146.

BILLINGTON, J. H. The prophetic role of art. In: The Icon and the Axe: An Interpretive History of Russian Culture. Nova York: Vintage Books, 1970, p. 329-345.

BURLIUK, D.; KRUCHONYKH, A.; MAIAKÓVSKI, V. Uma bofetada no gosto público. In: REIS, Daniel Aarão (Org.). Manifestos vermelhos e outros textos históricos da Revolução Russa. São Paulo: Penguin Classics Companhia das Letras, 2017, p. 72-73.

CHEREPOVA, T. I. Prokliátye vopróssy”- etítcheskoe iadro rússkoi filosófii i literatury [Questões malditas”o núcleo ético da filosofia e literatura russa]. Naútchnye Vedmosti BelGU. Seriia Filosófia, Sotsiologuia, Pravo, b. 24, n. 245, p. 195-198, 2016.

CHKLÓVSKI, V. Arte como procedimento. [Trad. David Gomiero Molina]. RUS, São Paulo, v. 10, n. 14, p. 153-176, 2019.

CHKLÓVSKI, V. Povesti o proze. Moscou: Khudôjestvennaia Literatura, 1966.

DOBRENKO, E.; TIHANOV, G. (org.). A History of Russian Literary Theory and Criticism - the Soviet Age and Beyond. Pitsburgo: Pittsburg University Press, 2011.

DOSTOIÉVSKI, F. M. Sonhos de Petersburgo em Verso e Prosa. In: Dois sonhos. Tradução Paulo Bezerra. São Paulo: Editora 34, 2012, p. 187-223.

DURÃO, F. O que é crítica literária. São Paulo: Parábola; Nankin Editorial, 2016.

EAGLETON, T. A função da crítica. Trad. Jefferson Luiz Camargo. São Paulo: Martins Fontes, 1991.

EIKHENBAUM, B. Nujna kritika. Jizn iskusstva, n. 4, p. 12, 1924.

EIKHENBAUM, B. Rietch o kritike. In: O literature: raboty raznykh liet. Moscou: Soviétski Pissátiel, 1987.

EIKHENBAUM, B. Molodoi Tolstoi. São Petersburgo, Berlin: Grjebina, 1922.

EIKHENBAUM, B. The Theory of the Formal Method. In: POMORSKA, K.; MATEJKA, L. Readings in Russian Poetics. Chicago: Dalkey Archive Press, 2002, p. 3-37.

ENGELGARDT, B. M. Formalni metod $v$ istorii literatury [O método formal na história da literatura]. Leningrado: Academia, 1927. 
ERLICH, V. Russian Formalism. History - doctrine. New Haven: Yale University Press, 1981.

HANSEN-LÖVE, A. A. "Bytologiia” mejdu faktami I funkstiami. Revue des Études Slaves, v. 57, n. 1. 1985, p. 91-103.

HOHENDAHL, P. U. The Institution of Criticism. Londres: Cornell University Press, 1982.

HOSKING, G. The birth of the intelligentsia. In: Russia: People and Empire. Cambridge, Massachusetts: Harvard University Press, 2001, p. 263-285.

KAPUSTINA, V. A. “Tolstie” jurnály: prochloe, nastoiáschee i buduschee. Vestnik KGU im. N. A. Nekrássova, n. 3, p. 105-107, 2007.

KEMPINSKA, O. A rejeição da estética na teoria formalista de Boris Eikhanbaum. Signótica, Goiânia, v. 30, n. 3, p. 365-380, 2018.

LACHMANN, R. Die “Verfremdung” und das “Neue Sehen” bei Viktor Sklovsij. Poetica, v. 3, 1970, p. $226-249$.

LVOV, V. Andrei Biéli i Boris Eikhenbaum: po linii jurnalnoi nauki [Andrie Biéli e Boris Eikhenbaum: pela linha da ciência de periódico]. Mediaalmanakh, p. 128-135, 2013.

MEDVIÉDEV, P. N. O método formal nos estudos literários: introdução critica a uma poética sociológica. Trad. Sheila Grillo e Ekaterina Vólkova. São Paulo: Contexto, 2012.

ORLOVA, E. I. Literatura, jurnalistka, filologuiia: pole vzaimodéistviia. Vestnik MGU Jurnalistka, n. 5, p. $77-$ $85,2012 \mathrm{a}$.

ORLOVA, E. I. Boris Eikhenbaum kak literturni kritik. Vopróssy literatury, n. 2, p. 30-46, 2012b.

PINTO, P; FRANCISCO JÚNIOR, M. R. Os estudos de Boris Eikhenbaum sobre a obra de Mikhail Lérmontov. RUS. São Paulo, v. 9, n. 12, p. 29-48, 2018.

POLONSKI, A. V. Publitsístika kak osóbi vid tvortcheskoi deiatelnosti. Naútchnye vedomosti Belgorodskogo Gossudárstvennogo Universiteta. Seria: Gumanitárnie naúki, v. 11, n. 51, p. 57-61, 2008.

PORMORSKA, K. Formalismo e futurismo. São Paulo: Perspectiva, 1972.

TIHANOV, G. The birth and death of literary theory: regimes of relevance in Russia and beyond. Stanford: Stanford University Press, 2019.

TODOROV, T. Crítica da crítica - um romance de aprendizagem. Trad. Maria Angélica Deângeli e Norma Wimmer. São Paulo: Editora Unesp, 2015. 